\title{
Biodiesel Production from Nyamplung (Calophyllum inophyllum) Oil using Ionic Liquid as A Catalyst and Microwave Heating System
}

\author{
Prima Astuti Handayani1 ${ }^{1,2}{ }^{*}$, A. Abdullah 1 , H. Hadiyanto ${ }^{1}$ \\ ${ }^{1}$ Department of Chemical Engineering, Diponegoro University, Jl. Prof. Soedarto, \\ Kampus Undip Tembalang, Semarang 50239, Indonesia \\ ${ }^{2}$ Department of Chemical Engineering, Universitas Negeri Semarang, \\ Kampus Unnes Sekaran Gunungpati, Semarang 50229, Indonesia
}

Received: 21 ${ }^{\text {st }}$ November 2016; Revised: $7^{\text {th }}$ March 2017; Accepted: 9th March 2017

Nyamplung (Calophyllum inophyllum) is a typical Indonesian plant. Its seed contains abundant inedible oil, and therefore it is potential for biodiesel feedstock. The current issues of biodiesel are longer reaction time of oil to biodiesel through transesterification reaction and lower biodiesel yield due to ineffective use of a homogenous catalyst. This work was aimed to use an ionic liquid as a catalyst and equipped with microwave heating as the heating system in order to increase the biodiesel yield and accelerate the process. Effects of the catalyst concentration and power of microwave irradiation to the biodiesel yield were studied. The ionic liquid of 1-butyl-3-methylimidazolium hydrogen sulfate $\left(\mathrm{BMIMHSO}_{4}\right)$ was used as a catalyst. The results showed that the highest biodiesel yield was achieved of $92.81 \%$ which was catalyzed by $\mathrm{IL}_{0.5} \mathrm{NaOH}_{0.5}\left(0.5\right.$ wt.\% $\left(\mathrm{BMIMHSO}_{4}\right)+0.5$ wt.\% $\left.\mathrm{NaOH}\right)$ with a methanol-to-oil molar ratio of 9 , a reaction time of 6 minutes, and the microwave temperature was 60 ${ }^{\circ} \mathrm{C}$. Copyright $\mathbb{C} 2017$ BCREC Group. All rights reserved

Keywords: biodiesel; ionic liquid; transesterification; microwave

How to Cite: Handayani, P.A., Abdullah, A., Hadiyanto, H. (2017). Biodiesel Production from Nyamplung (Calophyllum inophyllum) Oil using Ionic Liquid as A Catalyst and Microwave Heating System. Bulletin of Chemical Reaction Engineering \& Catalysis, 12 (2): 293-298 (doi:10.9767/bcrec.12.2.807.293298)

Permalink/DOI: http://dx.doi.org/10.9767/bcrec.12.2.807.293-298

\section{Introduction}

Energy crisis leads to the increase of biodiesel production as a renewable fuel which utilizes vegetable oil as raw material. Biodiesel technologies continue to develop fast esterification and higher obtained yield. Therefore, the process intensification in this area is a very paramount issue. The nyamplung (Calophyllum inophyllum) is one of the oil contained plants, and its source is abundant in

*) Corresponding Author

E-mail: prima@mail.unnes.ac.id (Handayani, P.A.)
Indonesia. The nyamplung seed contains $75 \%$ oil, and most of the oil is unsaturated fatty acid [1].

Biodiesel can be produced through a transesterification reaction between triglycerides and methanol using a catalyst in order to enhance the reaction rate. Generally, a base catalyst in the transesterification reaction can be carried out at a lower temperature and has shorter reaction time compared to an acid catalyst [2].

Ionic liquids are a new eco-friendly catalyst which is a type of organic salt composed by 
anions and cations which have a low vapor pressure and as a liquid phase at temperatures below $100{ }^{\circ} \mathrm{C}$ [3]. As a catalyst, the ionic liquids has a high catalytic activity, good stability, easily separate from the product, and environmental friendly [4]. The use of the ionic liquid catalyst in the biodiesel production could give more advantages in economic and environmental aspects. In addition, the heating process is required to increase the reaction rate. Microwave as the heating power in the transesterification reaction is more efficient than the conventional heating [5]. The microwave energy can go through to the inside of the material, and the energy is transferred to the material through interfacial polarization mechanism. The mechanism is the combination of dipolar polarization and ion conduction to produce localized and fast heating in the reaction [5]. The conventional heating has some significant drawbacks depend on the material thermal conductivity, specific heat, and heat loss to the environment [6]. Lin et al. [6] investigated that the transesterification reaction using the microwave and produced high biodiesel yield of $99 . \%$ at a reaction time of 6 minutes.

Elsheikh et al. [7] studied three different ionic liquids catalyst, and they are: 1-butylimidazolium hydrogen sulfate, 1-methylimidazolium hydrogen sulfate, and 1-butyl-3-methyl-imidazolium hydrogen sulfate in biodiesel production. Each catalyst activities has been studied toward their reaction of esterification to CPO raw material. The result of the study showed that 1-butyl-3-methylimidazolium hydrogen sulfate catalyst activity was better than the other catalysts. Fauzi and Amin [8] have conducted esterification process of oleat acid by using ionic liquid 1-butil-3-methylimidazolium hydrogen sulfate catalyst. The optimal achievement resulted in $81.2 \%$ methyl oleic yield on methanol-oleic acid of the molar ratio of 9:1, 0.06 moles of catalyst, $87^{\circ} \mathrm{C}$ temperature reaction, and $5.2 \mathrm{~h}$ reaction time. Meanwhile, Lin et al. [9] also studied the use of 4-alil-4-methylmorpholin-4-ium bromin $([\mathrm{MorMeA}][\mathrm{Br}])+\mathrm{NaOH}$ as a catalyst on microwave heating to enhance the methyl ester yield. The highest yield was achieved of $99.4 \%$ by using $\mathrm{IL}_{1} \mathrm{NaOH}_{0.75}$ ( 1 wt\% $[\mathrm{MorMeA}][\mathrm{Br}]+$ $0.75 \%$ wt $\mathrm{NaOH})$ catalyst; it was reached on the molar ratio of methanol-to-oil of 9 , the reaction time of 6 minutes, and temperature of $70{ }^{\circ} \mathrm{C}$. Lin et al. [6] also reported that microwave heating system has better performance than the conventional heating system, faster process, energy efficient and economic. Based on previous studies, the implementation of wave heating and 1-butyl-3-methyl-imidazolium hydrogen sulfate $\left(\mathrm{BMIMHSO}_{4}\right)+\mathrm{NaOH}$ catalyst never been studied. Therefore, the objective of this research is to evaluate the use of microwave heating and an ionic liquid to enhance the transesterification process. The study elaborates the effect of the amount of catalyst and type of catalyst as well as the variation of the power of microwave heating of performance of reaction.

\section{Materials and Methods}

\subsection{Materials}

The ionic liquid catalyst of 1 butyl-3-methyl imidazolium hydrogen sulfate $\left(\mathrm{BMIMHSO}_{4}\right)$ is analytical grade with the purity of $95 \%$ and purchased from Sigma-Aldrich. Methanol and sodium hydroxide $(\mathrm{NaOH})$ have the purity of $99.99 \%$ and $99 \%$, respectively, and supplied by Merck. Crude of Calophyllum inophyllum oil containing $12.8 \%$ of FFA was obtained from Kroya, Cilacap, Indonesia.

\subsection{Methods}

\subsubsection{Pre-treatment}

Nyamplung oil crude was purified using degumming and neutralization methods to remove the impurities present in the oil. A freshly prepared of phosphate acid $20 \%$ with the amount of $0.3 \%(\mathrm{v} / \mathrm{wt})$ was added into the oil then heated on a hot plate to temperature of $70{ }^{\circ} \mathrm{C}$ for 25 minutes. Furthermore, a saturated solution of sodium carbonate with a concentration of $20 \mathrm{~mL} / 100 \mathrm{~mL}$ oil was added into the oil then heated at $70{ }^{\circ} \mathrm{C}$ for $1 \mathrm{~h}$. Soap and other impurities were separated from the oil by decantation for 24 hours. The oil from decantation result was washed with water at $60-70{ }^{\circ} \mathrm{C}$ to obtain the neutral $\mathrm{pH}$ of the oil.

\subsubsection{Transesterification procedure}

The transesterification reaction was conducted in a four-necked batch reactor with a volume of $500 \mathrm{~mL}$ equipped with microwave, condenser, temperature sensor, and magnetic stirrer set at $600 \mathrm{rpm}$. A fixed amount of nyamplung oil was placed into the flask, which was preheated to the desired temperatures on a microwave before starting the reaction. The schematic apparatus of the microwave-assisted batch reactor is shown in Figure 1. The transesterification reaction was conducted in a catalyst concentration range of $0.5-1.5 \mathrm{wt} \%$, 
the oil and methanol molar ratio of 9:1, reaction temperature $60{ }^{\circ} \mathrm{C}$ and reaction time under microwave heating was 6 minutes. According to Lin et al. [6] the best yield of biodiesel was shown at the molar ratio of methanol to oil of 9 . The reaction mixture was added into the flask separator until two phases are formed in equilibrium. The upper phase consisted of methyl esters, and the lower phase contained the glycerol. The upper phase samples were taken and injected into Gas Chromatography-Mass Spectrometry (GC-MS) by syringe to determine the concentration of methyl esters. The methyl ester yield (product of methyl ester concentration and biodiesel yield) is defined as follows [6] :

Methyl ester yield $=C \times \frac{W_{b}}{W_{\text {oil }}} \times 100 \%$

where $C$ : methyl ester content (\%); $W_{b}$ : weight of biodiesel production (g); $W_{\text {oil }}$ : weight of the initial amount of nyamplung oil (g).

\section{Results and Discussion}

\subsection{Effect of catalyst concentration in the transesterification reaction using microwave heating}

The experiment used $\mathrm{NaOH}$ catalyst to study the effect of the catalyst toward the yield. The microwave system was operated at $60{ }^{\circ} \mathrm{C}$ temperature, the molar ratio of methanol to oil of 9:1 mole/mole, and reaction time of 6 minutes. Catalyst concentration was studied in the range of 0.5-1.5 wt\%. As shown in Figure 3, the biodiesel yields were $82.65 \%, 85.48 \%$, and

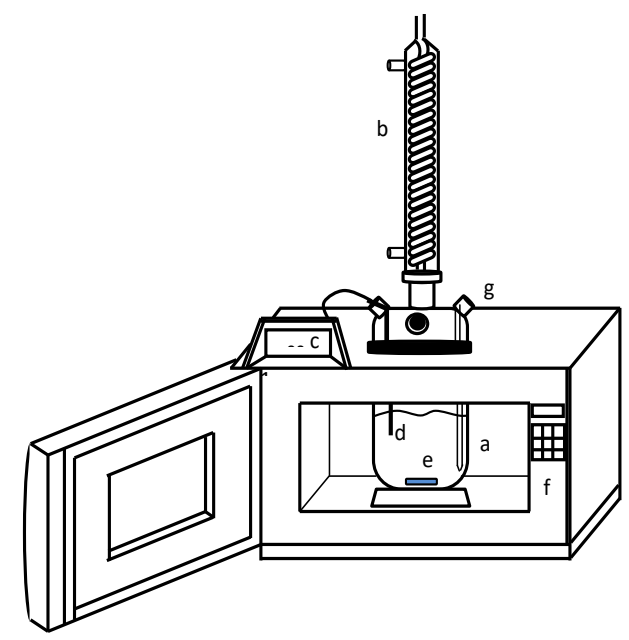

Figure 1. A set of batch reactor with microwave system. a, reactor; b, condenser; c, temperature display; d, temperature sensor; e, magnetic stirrer; f, control panel; g, input raw material
84.83\% over 0.5 wt\% $\mathrm{NaOH}, 1.0$ wt\% $\mathrm{NaOH}$, and $1.5 \mathrm{wt} \% \mathrm{NaOH}$, respectively. The best yield was achieved of $85.48 \%$ by adding $1 \% \mathrm{wt}$ $\mathrm{NaOH}$ catalyst. Reduction of biodiesel yield was found at $1-1.5 \%$ (wt) catalyst. The result showed that over balance of catalyst caused increasing amount of produced glycerol because of saponification occured [6].

The further experiment has been conducted at same amount of catalyst by using $\mathrm{NaOH}$ catalyst and $\mathrm{BMIMHSO}_{4}$ ionic liquid (1:1). The microwave system was set at temperature of $60{ }^{\circ} \mathrm{C}$, the molar ratio of methanol to oil of $9: 1$ mole/mole, and reaction time of 6 minutes. Figure 2 shows that the biodiesel yield was $89.69 \%, 92.81 \%$, and $92.54 \%$ of $0.5 \mathrm{wt} \%$ $\mathrm{BMIMHSO}_{4}: \mathrm{NaOH} \quad(1: 1), \quad 1.0 \quad$ wt $\%$ $\mathrm{BMIMHSO}_{4}: \mathrm{NaOH} \quad(1: 1)$, and $1.5 \quad$ wt $\%$ $\mathrm{BMIMHSO}_{4}: \mathrm{NaOH}$ (1:1), respectively. The experiment also showed that the best yield was $92.81 \%$ with 1.0 wt\% $\mathrm{BMIMHSO}_{4}: \mathrm{NaOH}(1: 1)$ catalyst. The result showed that the ionic liquid catalyst could enhance biodiesel yield and increase the use of $\mathrm{NaOH}$ catalyst in the amount of $0.5 \%$ wt. The ionic liquid catalyst is soluble in methanol, thereby increasing the contact area between the catalyst and the oil, therefore has a higher rate of reaction [10].

\subsection{Effect of [BMIMHSO 4 ]-NaOH catalyst concentration using microwave heating in the transesterification reaction}

The experiment was done by varying the catalyst composition of $\mathrm{BMIMHSO}_{4}$ and $\mathrm{NaOH}$ on transesterification reaction. The microwave

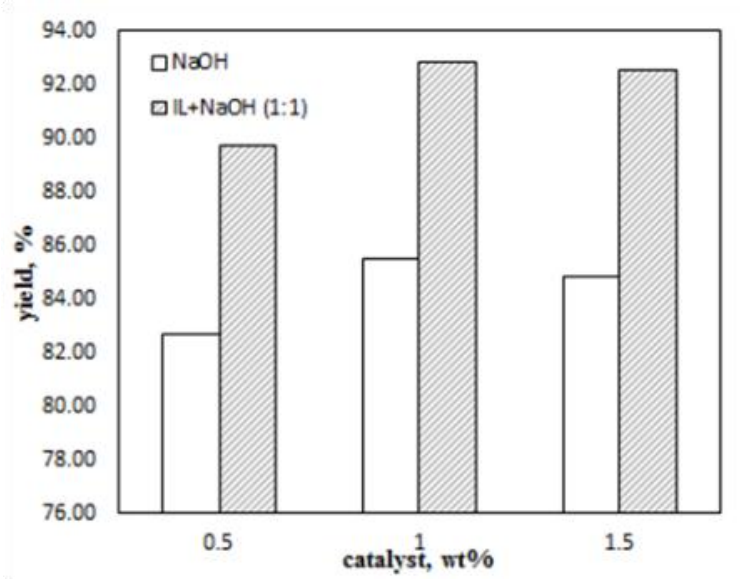

Figure 2. The effect of catalyst concentration to biodiesel yield during the microwave assisted esterification. The catalyst was compared between homogenous catalyst $(\mathrm{NaOH})$ and a mixed catalyst (Ionic Liquid and $\mathrm{NaOH}$ at $1: 1$ vol. ratio) in the range of $0.5-1.5 \%(\mathrm{w} / \mathrm{w})$ 
was set at temperature of $60{ }^{\circ} \mathrm{C}$, the molar ratio of methanol to oil was $9: 1$, and time reaction was 6 minutes. The composition of catalyst was varied according to ratio of $\mathrm{BMIMHSO}_{4}$ and $\mathrm{NaOH}$ of $3: 1,2: 1,1: 1,1: 2,1: 3,1: 4$, by adding 1 $\%$ wt amount of catalyst composition. Figure 3 shows that the yield increases at BMIMHSO $_{4}: \mathrm{NaOH}$ ratio of $3: 1,2: 1$, and $1: 1$, but no significant alteration on $1: 2,1: 3$, and $1: 4$. The over balance of catalyst has a negative effect on nyamplung biodiesel yield due to incomplete transesterification reaction between methanol and oil at shorter reaction time [9]. The best biodiesel yield was $92.81 \%$ produced at 1:1 $\mathrm{BMIMHSO}_{4}: \mathrm{NaOH}$ catalyst composition. Ullah et al. [11] reported the reaction mechanism of triglyceride and methanol using the ionic liquid catalyst (Figure 4).

\subsection{Effect of system microwave and conventional heating on the biodiesel yield}

The effect of the catalyst used in the transesterification reaction using conventional heating was conducted at a constant operation temperature of $60{ }^{\circ} \mathrm{C}$, methanol molar ratio to oil of $9: 1$, the catalyst concentration of $1 \% \mathrm{wt}$., and reaction time of 180 minutes. Figure 5 shows that the $\left[\mathrm{BMIMHSO}_{4}\right](1)+\mathrm{NaOH}(1) 1$ wt\% catalyst produces higher biodiesel yield $(93.99 \%)$ better than the use of $\mathrm{NaOH} 1 \mathrm{wt} \%$ (76.29\%). The mixed catalyst between $\left[\mathrm{BMIMHSO}_{4}\right]$ and $\mathrm{NaOH}$ have more reactivity compared to the $\mathrm{NaOH}$ catalyst because the ionic liquid catalyst has a high catalytic activity and good stability.

The use of the microwave as a heating power in the transesterification reaction using $\left[\mathrm{BMIMHSO}_{4}\right]-\mathrm{NaOH} 1 \mathrm{wt} \%$ catalyst with a

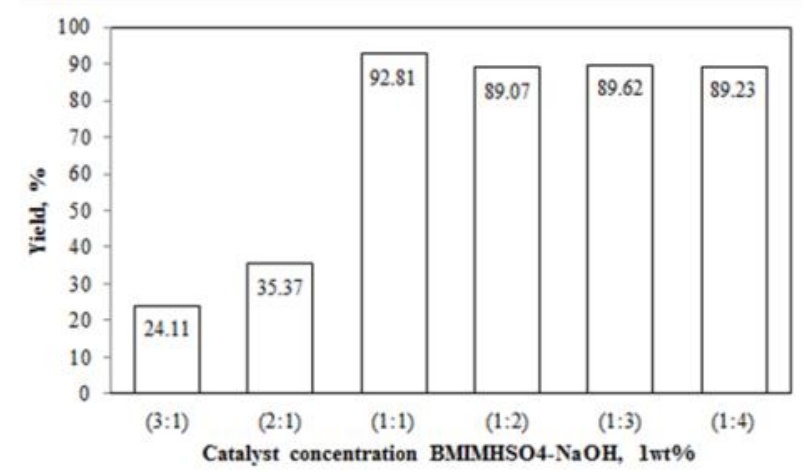

Figure 3. The effect of volume ratio of mixed catalyst (Ionic liquid and $\mathrm{NaOH}$ ) to biodiesel yield during microwave assisted esterification. The mixed catalyst was varied at $1 \%(\mathrm{w} / \mathrm{w})$ concentration in the mixture reaction time of 6 minutes can produce $92.81 \%$ biodiesel yield, whereas the conventional heating with a reaction time of 180 minutes resulted in $93.99 \%$ of biodiesel yield. Figure 3 shows that the use of the mixed catalyst ([BMIMHSO $\left.]_{4}\right]$ and $\mathrm{NaOH}$ ) gives better results compared with the use of $\mathrm{NaOH}$ catalyst. The use of $1 \%$ wt. $\mathrm{NaOH}$ catalyst using a microwave at 6 minutes of reaction time obtained $85.48 \%$ biodiesel yield, while the use of conventional heating with the reaction time of 180 minutes resulted in $76.29 \%$ biodiesel yield. Lin et al. [9] reported work on esterification of waste cooking oil (WCO) by microwave system using 4-allyl-4-methylmorpholin-4-ium bromine ([MorMeA $][\mathrm{Br}])+\mathrm{NaOH}$ ionic liquid catalyst. The highest biodiesel yield was $89.1 \%$ by using $1 \%$ wt. ([MorMeA] $[\mathrm{Br}])+0.75 \% \mathrm{wt}$ $\mathrm{NaOH}$ catalyst composition, the molar ratio of methanol to oil of 9 , the reaction temperature of $70{ }^{\circ} \mathrm{C}$, and the reaction time of 6 minutes [9]. In addition, Yuan et al. [12] studied the effect of the microwave system and conventional heating toward biodiesel yield by used of $\mathrm{H}_{2} \mathrm{SO}_{4} / \mathrm{C}$ catalyst, the molar ratio of methanol:castor oil of 12 , and the reaction temperature of $55^{\circ} \mathrm{C}$. The reaction reached the balance after 60 minutes of $94 \%$ yields with microwave system, meanwhile, with conventional
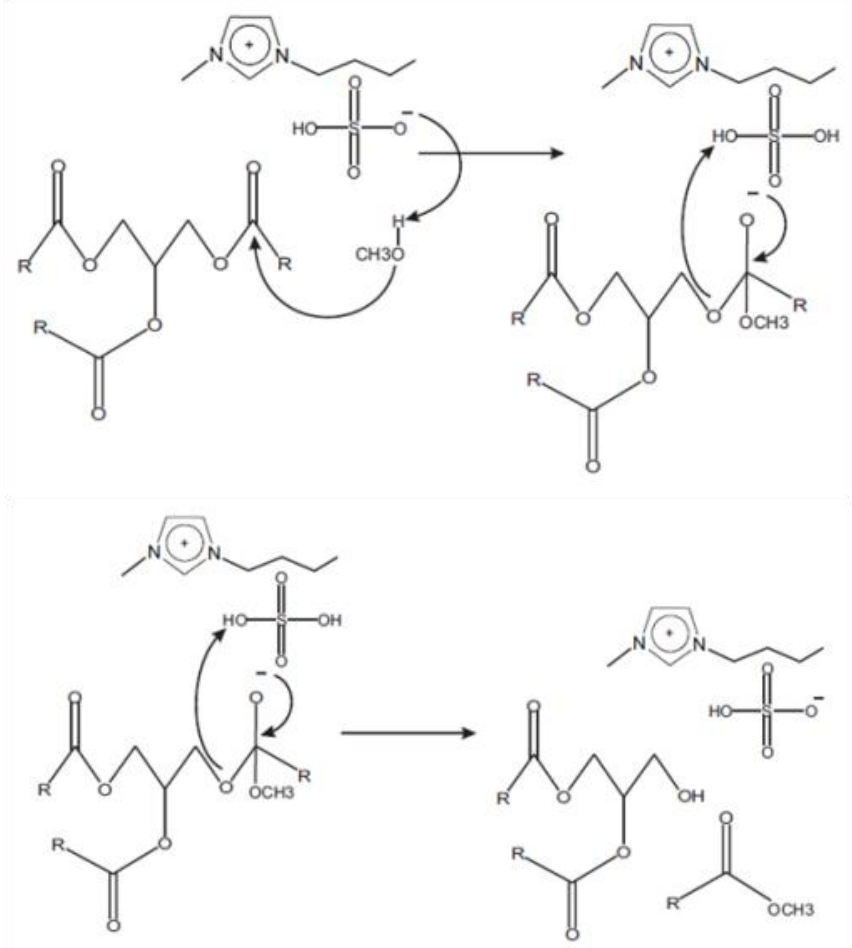

Figure 4. The reaction mechanism of triglyceride and methanol using the ionic liquid [BMIMHSO4] as catalyst [11] 
heating, the reaction reach the balance after 180 minutes of $70 \%$ yields. The reaction between methanol and oil were getting better because it was exposed by the microwave and then enhance the reaction.

Methanol is one of alcohol that consists of polar compounds [13] which interact to adsorb the microwave, while the nonpolar molecule is an inert [14]. Microwave radiation can increase the chemical reaction due to its capability to deliver the energy directly to the reactant so that the energy transfer is more effective than the conventional heating [15].

\section{Conclusions}

The result of the study showed that [BMIMHSO ${ }_{4}$ ] could increase nyamplung biodiesel yield and reduce the use of $\mathrm{NaOH} 0.5$ $\%$ wt catalyst. The best yield was produced at $\mathrm{NaOH} 1 \%$ wt catalyst, the methanol molar ratio to oil of 9 , the reaction time of 6 minutes, and the microwave temperature of $60{ }^{\circ} \mathrm{C}$. Meanwhile for the $\mathrm{BMIMHSO}_{4}(1): \mathrm{NaOH}(1) \quad 1 \% \mathrm{wt}$ catalyst, the best yield was achieved of $92.81 \%$ with molar ratio of methanol to oil of 9 , the reaction time of 6 minutes, and the microwave temperature of $60^{\circ} \mathrm{C}$. There were no significant differences in yield by variation of mixed catalyst (ionic liquid: $\mathrm{NaOH}$ ) at 1:2,1:3 and 1:4 . This concluded that by increasing $\mathrm{NaOH}$ in mixed catalyst will not give any improvements of reaction. The conventional heating system resulted in a yield of $93.99 \%$ by using the mixed catalyst of $\mathrm{BMIMHSO}_{4}: \mathrm{NaOH}$, while the homogenous catalyst $(\mathrm{NaOH})$ only gained 72.69 $\%$ yield at process condition of $1 \%$-wt catalyst

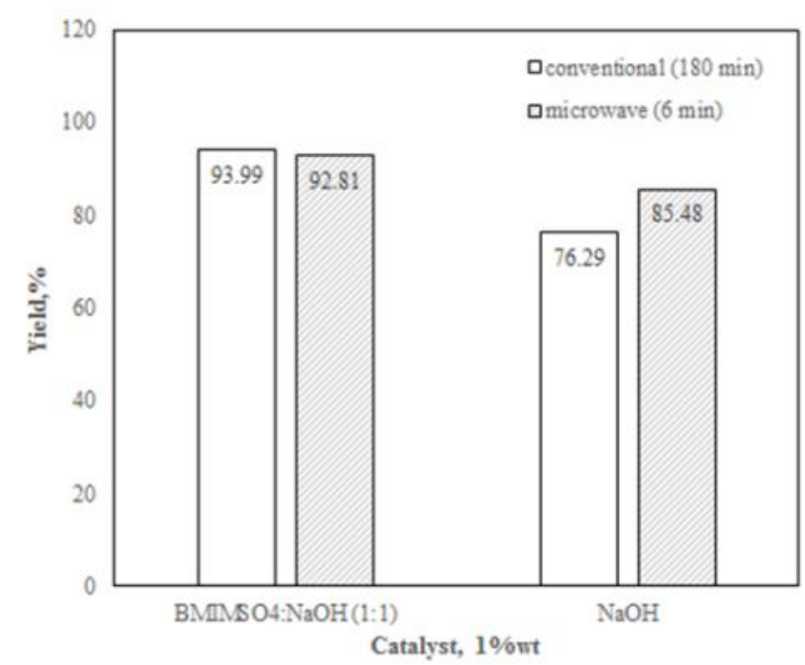

Figure 5. Effect of microwave and conventional heating in the transesterifiation reaction of the biodiesel yield and $60{ }^{\circ} \mathrm{C}$ reaction temperature. Furthermore, the used of microwave heating make the transesterification reaction faster than the use of conventional heating. The use of the mixed $\left[\mathrm{BMIMHSO}_{4}\right]+\mathrm{NaOH}$ catalyst and the microwave can be a promising catalyst and heater in the transesterification reaction.

\section{References}

[1] Ong, H.C., Mahlia, T.M.I., Masjuki, H.H., Norhasyima, R.S. (2011). Comparison of Palm Oil, Jatropha Curcas, and Calophyllum Inophyllum for Biodiesel: A Review. Renewable and Sustainable Energy 15: 35013515.

[2] Fukuda, H., Kondo, A., Noda, H. (2001). Biodiesel fuel production by transesterificationof oils. Journal of Bioscience and Bioengineering. 92: 405-416.

[3] Fauzi, A.H.M., Amin, N.A.S. (2012). An Overview of Ionic Liquids as Solvents in Biodiesel Synthesis. Renewable and Sustainable Energy Reviews. 16: 5770-5786.

[4] Wu, Q., Chen, H., Han, M., Wang, D., Wang, J. (2007). Transesterification of Cottonseed Oil Catalyzed by Brønsted Acidic Ionic Liquids. Ind. Eng. Chem. Res. 46: 7955-7960.

[5] Gude, V.G., Patil, P., Guerra, E.M., Deng, S., Nirmnalakhanda, N. (2013). Microwave Energy Potential for Biodiesel Production (Review). Sustainable Chemical Processes. 1: 1-31.

[6] Lin, Y.C., Yang, P.M., Chen, S.C., Tu, Y.T., Lin, J.F. (2013). Biodiesel Production Assisted by 4-Allyl-4-Methylmorpholin-4-Ium Bromine Ionic liquid and a Microwave Heating System. Applied Thermal Engineering. 61(2): 570-576.

[7] Elsheikh, Y.A., Man, Z., Bustam, M.A., Yusup, S., Wilfred C.D. (2011). Brønsted Imidazolium Ionic liquid: Synthesis And Comparison of Their Catalytic Activities as Pre-Catalyst for Biodiesel Production Through Two Stage Process. Energy Conversion and Management. 52: 804-809.

[8] Fauzi, A.H.M., Amin, N.A. (2013) Optimization of Oleic Acid Esterification Catalyzed by Ionic Liquid for Green Biodiesel Synthesis. Energy Conversion and Management. 76: 818-827.

[9] Lin, Y.C., Yang, P.M., Chen, S.C., Lin, J.F. (2013). Improving Biodiesel Yields from Waste Cooking Oil using Ionic Liquid as catalyst with a Microwave Heating System. Fuel Processing Technology. 115: 57-62.

[10] Han, M., Yi, W., Wu, Q., Liu, Y, Hong, Y., Wang, D. (2009). Preparation of Biodiesel 
from Waste Oils Catalyzed by a Bronsted Acidic Ionic Liquid. Bioresource Technology. 100: $2308-2310$.

[11] Ullah, Z., Bustam, M. A., Man, Z. (2015). Biodiesel Production from Waste Cooking Oil by Acidic Ionic liquid as a Catalyst. Renewable Energy. 77: 521-526.

[12] Yuan, H., Yang, B.L., Zhu G.L. (2009). Syntesis of Biodiesel using Microwave Absorption Catalyst. Energy \& Fuels 23: 548552.

[13] Sherbiny, S.A.E., Refaat, A.A., Sheltaway, S.T.E. (2010). Production of Biodiesel using The Microwave Technique. Journal of Advanced Research. 1: 309-314.
[14] Perreux, L., Loupy, A. (2001). A Tentative Rationalization of Microwave Effects in Organic Synthesis According to The Reaction Medium, and Mechanistic Considerations. Tetrahedron. 57: 9199-9223.

[15] Motasemi, F., Ani, F.N. (2012). A Review on Microwave-Assisted Production of Biodiesel. Renewable and Sustainable Energy Reviews. 16(7): 4719-4733.

Selected and Revised Papers from The 2nd International Seminar on Chemistry (ISoC 2016) (Surabaya, 26-27 July 2016) (http://chem.its.ac.id/isoc-2016/) after Peer-reviewed by Scientific Committee of ISoC 2016 and Peer-Reviewers of BCREC journal 